\title{
BMJ Open Adolescent follow-up in the Health Outcomes and Measures of the Environment (HOME) Study: cohort profile
}

\author{
Joseph M Braun (D , ${ }^{1}$ Jessie P Buckley, ${ }^{2}$ Kim M Cecil, ${ }^{3}$ Aimin Chen, ${ }^{4}$ \\ Heidi J Kalkwarf, ${ }^{5}$ Bruce P Lanphear, ${ }^{6}$ Yingying $\mathrm{Xu},{ }^{5}$ Anastasia Woeste, ${ }^{5}$ \\ Kimberly Yolton ${ }^{5}$
}

To cite: Braun JM, Buckley JP, Cecil KM, et al. Adolescent follow-up in the Health Outcomes and Measures of the Environment (HOME) Study: cohort profile. BMJ Open 2020;10:e034838. doi:10.1136/ bmjopen-2019-034838

- Prepublication history for this paper is available online. To view these files, please visit the journal online (http://dx.doi org/10.1136/bmjopen-2019034838).

Received 07 October 2019 Revised 11 March 2020 Accepted 20 April 2020
Check for updates

(C) Author(s) (or their employer(s)) 2020. Re-use permitted under CC BY-NC. No commercial re-use. See rights and permissions. Published by BMJ.

For numbered affiliations see end of article.

Correspondence to Dr Joseph M Braun; joseph_braun_1@brown.edu

\section{ABSTRACT}

Purpose Environmental chemical exposures may adversely affect an array of adolescent health outcomes. Thus, we used the Health Outcomes and Measures of the Environment (HOME) study, a prospective cohort that recruited pregnant women and conducted longitudinal follow-up on children over the first 12 years of life, to determine if and when chemical exposures affect adolescent health.

Participants We recruited 468 pregnant women (age range: $18-45$ years) from the Cincinnati, Ohio region to participate in a cohort study between March 2003 and January 2006. Follow-up included two clinic and one home visits during pregnancy, a delivery hospital visit, and four home and six clinic visits when children were aged 4 weeks and 1, 2, 3, 4, 5 and 8 years. Of 441 children available for follow-up, $396(90 \%)$ completed at least one follow-up and 256 (58\%) completed the most recent follow-up at 12 years of age (range: 11-14).

Findings to date Our new measures include maternal/ child report of internalising symptoms, neuroimaging, dual-energy X-ray absorptiometry-derived estimates of lean/adipose tissue and bone mineral density, and cardiometabolic risk biomarkers. We assessed adolescent exposure to perfluoroalkyl substances, phenols, phthalates and flame retardants. Participants completing follow-up at 12 years of age were similar to the original cohort in terms of baseline factors. Most children had typical and expected values for this age on measures of internalising symptoms, body composition, bone density and cardiometabolic risk markers. Notably, $36 \%$ and $11 \%$ of children had scores indicative of potential anxiety and depressive disorders, respectively. Approximately $35 \%$ of children were overweight or obese, with higher prevalence among girls. Thirty-three per cent of children had borderline or high triglyceride concentrations (>90 mg/dL).

Future plans We will examine associations of early life environmental chemical exposures with adolescent health measures while considering potential periods of heightened susceptibility and mixture effects.

Trial registration number NCT00129324.

\section{INTRODUCTION}

Environmental exposures experienced by the gametes, fetus, infant, child or adolescent
Strengths and limitations of this study

- Repeated assessment of environmental chemical exposure during gestation, infancy, childhood and adolescence allows us to investigate periods of heightened susceptibility.

- High-quality and longitudinal measurements of physical, behavioural and mental health provide opportunities to examine trajectories of multiple childhood health outcomes.

- Attrition over the course of follow-up is one of the main limitations of the Health Outcomes and Measures of the Environment (HOME) Study (42\% attrition at 12 -year study visit).

- The modest sample size limits the statistical power to examine relatively small effects or clinical diagnoses.

- Our eligibility criteria may reduce the generalisability of our findings to other populations.

may increase the risk of later life disease. Well-established examples of environmental factors affecting later-life health include the increased risk of vaginal clear cell carcinoma and several reproductive disorders following in utero diethylstilbestrol exposure, as well as cognitive decrements in children with prenatal mercury or childhood lead exposure. ${ }^{1-4}$ These studies indicate the presence of periods of heightened developmental susceptibility to some exposures.

There is concern that exposure to environmental chemicals during susceptible periods may increase the risk of adverse childhood health outcomes. ${ }^{5-7}$ Work from our research group shows that exposure to environmental chemicals and their mixtures is associated with reduced fetal growth, ${ }^{8} 9$ neurobehavioural deficits, ${ }^{10}{ }^{11}$ respiratory problems ${ }^{12}{ }^{13}$ and excess adiposity. ${ }^{14}$ Moreover, we found that the association of some chemicals with 
childhood health depends on the timing of exposure. ${ }^{115}$ However, there are substantial gaps in our knowledge about the persistence of these effects into adolescence, especially for outcomes unique to adolescence, including puberty ${ }^{16}$ bone health ${ }^{17}$ and internalising disorders. ${ }^{18}$

Relatedly, there is little research examining the impact of adolescent chemical exposures on health. Adolescence may be a period of heightened susceptibility as studies of the Nigerian Civil War and Cambodian famine indicate that famine during adolescence had greater impacts on adult height than famine during other periods. ${ }^{19}$ Moreover, some aspects of gestational and adolescent development share common biological pathways (eg, neurodevelopment). ${ }^{21}$ Thus, exposure to chemicals during adolescence may adversely affect neurobehaviour, bone health, asthma/allergy, obesity and cardiometabolic health.

Ensuring that adolescents achieve their full potential is of profound public health importance given that the 1.2 billion adolescents worldwide $(16 \%$ of the population) will become tomorrow's leaders, labourers and parents. ${ }^{22}$ Interventions targeting adolescents have great potential for high economic and social returns. ${ }^{23}$ Thus, we conducted a new follow-up on adolescents from the Health Outcomes and Measures of the Environment (HOME) Study to fill critical gaps in our knowledge about the potential effects of chemical exposures across the lifespan on adolescent health.

\section{COHORT DESCRIPTION \\ Overview}

The HOME Study is a prospective pregnancy and birth cohort study that enrolled 468 pregnant women from the greater Cincinnati, Ohio region from 2003 to 2006 and conducted longitudinal follow-up on children shortly after birth and at 4 weeks and 1, 2, 3, 4, 5 and 8 years of age. ${ }^{24}$ As previously described, the HOME Study was designed to quantify the effects of low-level environmental toxicant exposures on children's risk of allergy, asthma, obesity and neurobehavioural disorders. ${ }^{24}$ During pregnancy and childhood, we repeatedly collected maternal and child biospecimens and environmental samples, and administeredta neurobehavioural batteries, clinical examinations and questionnaires longitudinally to both mothers and their children.

We completed a new phase of data collection when children were 12 years of age (range: 11-14), at which time we assessed several dimensions of children's health and well-being that were not previously measured (table 1). This latest phase of follow-up included detailed assessments of internalising symptoms (ie, anxiety and depression), neuroimaging, body composition, bone health and cardiometabolic health, as well as continued assessment of children's allergies, asthma, respiratory health, anthropometry and neurobehaviour. In addition, we assessed children's diet, physical activity and sleep, and collected an array of biospecimens from children. Moreover, we measured leucocyte DNA methylation and metabolomics
Table 1 Summary of measurements collected from HOME Study children and their mothers at 12 years of age (Cincinnati, Ohio, 2016-2018)

\begin{tabular}{|c|c|}
\hline $\begin{array}{l}\text { Measurement } \\
\text { category }\end{array}$ & Measurement or sample \\
\hline \multirow{8}{*}{$\begin{array}{l}\text { Internalising } \\
\text { symptoms and } \\
\text { neurobehaviour }\end{array}$} & Anxiety \\
\hline & Depression \\
\hline & Memory \\
\hline & Fine motor skills \\
\hline & Executive functions \\
\hline & Social behaviours \\
\hline & Social problem solving \\
\hline & $\begin{array}{l}\text { Problem behaviours (eg, attention-deficit/ } \\
\text { hyperactivity disorder) } \\
\text { Adaptive behaviours }\end{array}$ \\
\hline \multirow[t]{2}{*}{ Brain imaging } & $\begin{array}{l}\text { MRI } \\
\text { Magnetic resonance spectroscopy } \\
\text { Diffusion MRI }\end{array}$ \\
\hline & Functional MRI \\
\hline
\end{tabular}

Body composition Fat and lean mass, visceral fat mass

and bone health Whole body, lumbar spine, forearm, and hip bone mineral content and density

Weight, height and waist/hip circumferences

\section{Cardiometabolic Blood pressure}

risk factors Heart rate

Fasting insulin and glucose

Fasting HDL, LDL, total cholesterol and triglycerides

Leptin and adiponectin

Central adiposity

$\begin{array}{ll}\text { Biospecimens } & \text { Blood-serum and whole blood } \\ & \text { Buccal cells } \\ & \text { Hair } \\ & \text { Stool } \\ & \text { Urine } \\ & \text { Shed deciduous teeth } \\ & \text { Phthalates, phenols, polybrominated diphenyl } \\ \text { Chemical } & \text { ether flame retardants, organophosphate flame } \\ \text { exposures } & \text { retardants and perfluoroalkyl substances }\end{array}$

\begin{tabular}{ll} 
Other biomarkers & $\begin{array}{l}\text { High-resolution metabolomics } \\
\text { Leucocyte DNA methylation } \\
\text { Vitamin D metabolites } \\
\text { Urine drug screen }\end{array}$ \\
Physical activity & $\begin{array}{l}\text { Questionnaire } \\
\text { Accelerometer }\end{array}$ \\
Diet & $\begin{array}{l}3 \times 24 \text { hour Dietary recalls } \\
\text { Eating behaviours }\end{array}$ \\
Sleep & $\begin{array}{l}\text { Questionnaire } \\
\text { Actigraphy }\end{array}$ \\
Pubertal & $\begin{array}{l}\text { Self-assessed Tanner staging } \\
\text { Lutenising and follicle-stimulating hormones } \\
\text { development }\end{array}$ \\
& $\begin{array}{l}\text { Estradiol, testosterone and } \\
\text { dehydroepiandrosterone sulfate }\end{array}$ \\
\hline
\end{tabular}

Continued 


\begin{tabular}{ll}
\hline $\begin{array}{l}\text { Table } 1 \text { Continued } \\
\text { Measurement } \\
\text { category }\end{array}$ & Measurement or sample \\
\hline Questionnaires & $\begin{array}{l}\text { Substance Use } \\
\text { School Outcomes } \\
\\
\end{array}$ \\
& Sociodemographics \\
& Fother-Child Relationship \\
& Momily Medical History \\
& Environmental Exposures
\end{tabular}

ADHD, Attention-deficit/hyperactivity disorder; HDL, high-density lipoprotein; HOME, The Health Outcomes and Measures of the Environment; LDL, low-density lipoprotein.

during gestation, childhood and adolescence, as these may be important health outcomes or potential mediators in the relationships between early life exposures and child health. Finally, we assessed mother's anthropometry, blood pressure and several features of her mental health, as well as collected information about the health history of fathers and grandparents.

\section{Eligibility and follow-up}

From March 2003 to January 2006, we recruited 468 pregnant women living in a five-county region of the Cincinnati, Ohio metropolitan area (Butler, Clermont, Hamilton and Warren counties) and Northern Kentucky (Campbell County) to participate in a longitudinal pregnancy and birth cohort study. Sixty-seven women dropped out during pregnancy during the run-in phase of a randomised controlled trial of residential lead and injury hazard controls nested within the cohort. ${ }^{25}{ }^{26}$ From 2003 to 2014, we conducted up to 11 in-person follow-up visits on 410 eligible children (390 singletons and 10 twin sets) at the delivery hospital, our study clinic or participant's homes when children were approximately 1 day, 4 weeks, and 1, 2, 3, 4, 5 and 8 years of age; follow-up rates ranged from $48 \%$ (age 4 years) to $94 \%$ (age 4 weeks).

From June 2016 to April 2019, we invited 441 children (offspring of 431 mothers; $92 \%$ of all live births) and their birth mother or primary caregiver (referred to as mother hereafter) to return to our study clinic when children were on average 12.4 years of age (SD: 0.7, range: $11-14.1)$. We did not contact $38(8 \%)$ participants because the fetus or child was deceased, they did not provide prenatal biospecimens or they indicated that they did not want to be contacted for future study visits. We restricted the upper limit of our age range to $<14.1$ years to reduce the variability of our study outcomes related to age. At the 12-year study visit, we attempted to contact 30 mothers who dropped out during the run-in phase of the randomised trial; 10 of these children $(8$ singletons and 1 twin set) completed the 12-year study visit.

We completed follow-up on 256 children (242 singletons and 7 twin sets) ( $58.0 \%$ of children). Nine children conducted follow-up by telephone or mail, only completing study-related questionnaires. Among those 185 who did not complete follow-up, 99 (54\%) refused to participate, 23 (12\%) were lost to follow-up and 63 (34\%) turned 14 years old before we could complete follow-up.

We employed conventional methods like newsletters, mailings, providing Saturday visits, and frequent phone calls, text messages and emails to study participants to increase participation at this study visit. In addition, we used the LexisNexis Accurint service to obtain updated contact information for mothers and contacted participant's friends or family members. We also created a Facebook page that we used to announce study visits, publicise study results, share other study-related information and communicate with participants. Finally, we visited some participant's residences to tell them about the study visit, leave information and a small gift, and attempt to schedule a follow-up visit.

\section{Randomised trial}

Nested within the HOME Study is a randomised clinical trial of two interventions designed to reduce residential lead and injury hazards; we previously described the results of these trials. ${ }^{25}{ }^{26}$ Briefly, we randomly assigned pregnant women to either the residential lead or injury hazard intervention. By 32 weeks of gestation and before delivery, the lead hazard intervention group received a combination of activities designed to reduce residential lead exposure. Families assigned to the control group received an injury prevention intervention before children were aged 6 months.

\section{Patient and public involvement}

A community advisory board provided feedback on the original design of the HOME Study before the study began. Before initiating any new follow-up, we conducted pilot testing to ensure that the visit length and types of assessments were appropriate. At more recent childhood follow-up visits, we collected information regarding the visit length and experience from participants and used this to inform the development of subsequent visits. We previously reported back concentrations of environmental chemical biomarkers to participants while also providing contextual information. Finally, we reported clinically significant findings to participants and their medical providers (eg, hypercholesterolaemia).

\section{Adolescent follow-up measurements}

At the latest HOME Study visit, we conducted detailed assessments of children's neurobehaviour, body composition, bone health and cardiometabolic risk. In addition, we assessed multiple risk factors for these health outcomes that might be confounders, mediators or modifiers of associations between chemical exposures and these health outcomes (table 1).

\section{Neurobehaviour and neuroimaging}

We measured several domains of children's neurobehaviour, with an emphasis on internalising symptoms. To assess children's anxiety, children completed the 
Table 2 Neuroimaging measures obtained from HOME Study children at 12 years of age

\begin{tabular}{|c|c|c|c|}
\hline Measure & Method & Outcome variables & Purpose \\
\hline Structure & Volumetric & Volume $\left(\mathrm{mm}^{3}\right)$ & $\begin{array}{l}\text { Total grey matter, white matter, CSF and } \\
\text { regional volumes; cortical thickness }\end{array}$ \\
\hline $\begin{array}{l}\text { Structure \& } \\
\text { function }\end{array}$ & MRS & $\begin{array}{l}\text { Concentrations of } N \text {-acetylaspartate, creatine, } \\
\text { choline, myo-inositol and glutamate }\end{array}$ & Neural structure and metabolism \\
\hline Function & fMRI & $\begin{array}{l}\text { Signal activation; global and local efficiency; } \\
\text { transivity from networks }\end{array}$ & $\begin{array}{l}\text { Functional connectivity features of the neural } \\
\text { networks }\end{array}$ \\
\hline
\end{tabular}

CSF, cerebrospinal fluid; fMRI, functional MRI; HOME, The Health Outcomes and Measures of the Environment; MRS, magnetic resonance spectroscopy.

Spence Children's Anxiety Scale, and both mothers and children completed the Screen for Child Anxiety Related Disorders. ${ }^{27}$ Children and their mothers selfreported depressive symptoms with the Child Depression Inventory-II and Beck Depression Inventory-II, respectively. ${ }^{29} 30$ Both mothers and children completed the Behavior Rating Inventory of Executive Function and Behavioral Assessment System for Children-3 to assess children's executive function and problem/adaptive behaviours, respectively. ${ }^{31} 32$ We assessed children's social behaviours by administering the Social Responsiveness Scale-2 to mothers, the Social Skills Improvement System scale to mothers and children, and the Social Problem Solving Scale to children. ${ }^{33-35}$ We administered the Child and Adolescent Memory Profile and Grooved Pegboard to assess children's memory and fine motor skills, respectively. ${ }^{36} 37$ Finally, mothers completed the Child Eating Behavior Questionnaire to measure eight dimensions of children's appetite and eating behaviours. ${ }^{38} 39$

Using a $3 \mathrm{~T}$, whole-body magnetic resonance scanner with a 32-channel head coil, we conducted a neuroimaging protocol on 199 (188 singletons and 11 twins (1 randomly selected)) children without braces, metal implants, significant anxiety or claustrophobia, prior brain surgeries or communication barriers. The measurements included volumetric MRI, proton magnetic resonance spectroscopy (MRS), diffusion tensor imaging and functional MRI (fMRI) (details in table 2). Two fMRI techniques were acquired: a block paradigm design with a continuous performance task using a facial affect probe and a paradigm of free resting-state acquisition for functional connectivity analyses. Figure 1 shows the results for these four modalities from one cohort participant.

\section{Body composition, bone health and anthropometry}

We measured adipose and lean tissue mass of the whole body, extremities and abdomen as well as visceral fat using dual-energy X-ray absorptiometry with a Hologic Horizon densitometer. Using this same instrument, we estimated bone mineral content and density of the whole body, lumbar spine, hip and forearm. Experienced research assistants measured weight, standing height, and waist and hip circumferences in triplicate.

\section{Biospecimens}

We collected fasting blood, buccal cells, hair, urine and stool samples from children. To ensure that children
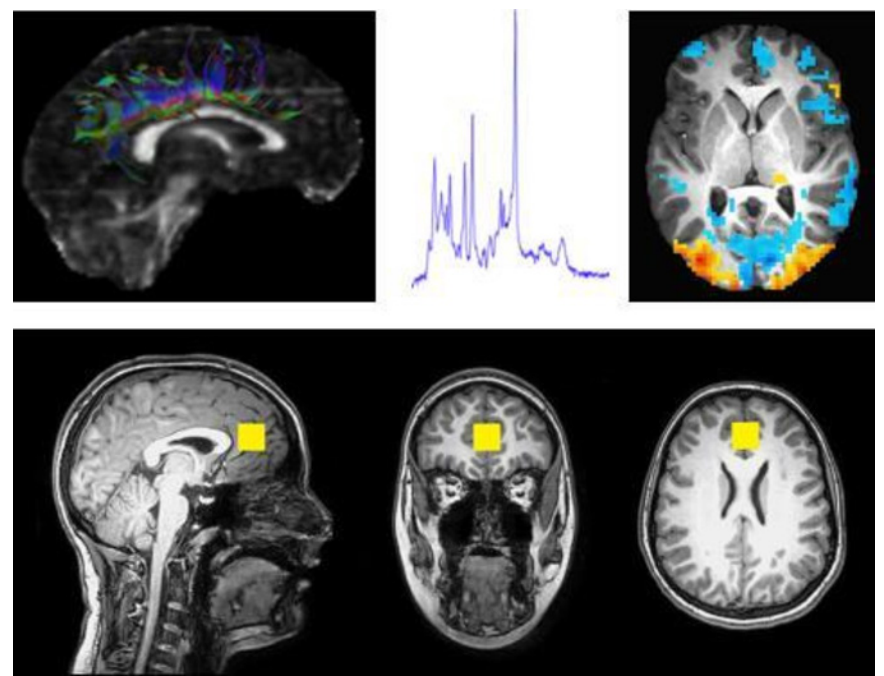

Figure 1 Illustrations of the multimodal neuroimaging protocol acquired from a HOME Study participant. Top left, a representation of white matter fibre tracks emerging from the cingulum determined using diffusion tensor imaging. Top centre, a spectral plot of relative concentrations of select neurochemicals within the perigenual anterior cingulate cortex acquired with MRS). Top right, a calculated activation MAP from a single slice of the brain during a continuous performance task that was measured with functional MRI. Bottom, anatomical images acquired with MRI; slices are oriented in the sagittal, coronal and axial planes. The yellow box denotes the location and volume $\left(8 \mathrm{~cm}^{3}\right)$ where the MRS sampling was acquired. The anatomical images are acquired at high resolution, on the order of $1 \mathrm{~mm}^{3}$, to enable volumetric and morphometric analyses. All images courtesy of Travis Beckwith, PhD and Kim M Cecil, PhD. HOME, Health Outcomes and Measures of the Environment; MAP, mean apparent propagator; MRS, magnetic resonance spectroscopy. 
arrived in a fasting state, we reminded parents the night before the study visit to have their child begin fasting at bedtime. In addition, we asked children if they ate anything since bedtime last night and brought children back for a fasting blood draw at a later date if they broke their fast before the study visit. In the 2 weeks after the study visit, children collected up to three stool samples on faecal occult blood test cards. ${ }^{40}$

Children returning for in-person visits provided urine $(n=247,95 \%)$, buccal cells $(n=246,96 \%)$, hair $(n=230$, $90 \%)$, blood ( $\mathrm{n}=209,82 \%)$ and up to three stool samples $(\mathrm{n}=172,67 \%)$. Missing blood collections were due to refusals $(n=28,11 \%)$ or difficulties with the blood collection (eg, fainting) $(\mathrm{n}=19,7 \%)$. We also collected 1159 shed deciduous teeth from 205 children. ${ }^{41}$ Blood and stool samples are stored in $-80^{\circ} \mathrm{C}$ freezers, whereas buccal cells and urine are stored at $-20^{\circ} \mathrm{C}$. Hair and teeth are stored at ambient indoor temperature in locked cabinets.

\section{Cardiometabolic risk markers}

We assessed several features of children's cardiometabolic health that have been associated with increased risk of adult cardiovascular disease. ${ }^{42-45}$ We measured waist circumference and dual-energy X-ray absorptiometryderived measures of central adiposity to classify children as centrally obese. ${ }^{46}{ }^{47}$ We took three sitting blood pressure and heart rate measurements, each $1 \mathrm{~min}$ apart, using a Dinamap Pro100 automated monitor. ${ }^{48}$ Finally, we quantified insulin, glucose, total cholesterol, lowdensity and high-density lipoproteins, triglyceride and haemoglobin A1C concentrations in fasting serum or whole blood samples.

\section{Chemical exposures}

Using biomarkers and questionnaires, we measured or plan to measure children's exposure to an array of environmental chemicals that have been implicated in the risk of neurobehavioural disorders and internalising symptoms, obesity, bone health and cardiometabolic dysfunction. ${ }^{6750}$ This includes serum concentrations of polychlorinated biphenyls (PCBs), per- and polyfluoroalkyl substances (PFAS) and polybrominated diphenyl ethers (PBDEs), as well as urinary concentrations of phthalates, phthalate replacements, phenols, phenol replacements and organophosphate flame retardants. We also administered questionnaires to parents and children about behaviours and the use of products related to these and other chemical exposures.

\section{Physical activity, diet and sleep}

We measured physical activity, diet and sleep as potential confounders of chemical exposure-outcome associations to account for variation in our outcomes related to them, or to investigate them as potential mediators or modifiers of associations between chemical exposures and childhood health. We measured physical activity over 7 days with an Actigraph accelerometer and administered a physical activity questionnaire. ${ }^{51-53}$ Trained research staff administered three 24-hour dietary recalls to children using the Nutrition Data Systems for Research software and foods database to assess total daily energy and macronutrient and micronutrient intake; we also calculated 2015 Healthy Eating Index scores. ${ }^{54}$ Mothers and their children completed the Adolescent Sleep Habits Questionnaire. In addition, we are able to derive sleep measures from the actigraphy data. ${ }^{556}$

\section{Other biomarkers}

We measured other biomarkers including leucocyte DNA methylation, ${ }^{57}$ high-resolution metabolomics, ${ }^{58}$ gonadal hormone concentrations and vitamin D metabolite concentrations. We also conducted a drug screen on children's urine using a clinical drug panel assay.

\section{Other data}

We measured sociodemographic factors including maternal (or caregiver) and child race/ethnicity, age, education, marital status, employment, insurance and household income. We assessed mother's (or caregiver's) psychological symptoms and parenting relationship with the child using the Symptom Checklist-90-Revised and Parenting Relationship Questionnaire, respectively. ${ }^{59} 60$ We also measured mother's weight, standing height, waist and hip circumference, blood pressure and heart rate as described earlier. In addition, we administered a questionnaire about the mother's and biological or non-biological father's history of cardiometabolic disease. To assess child puberty, we measured serum gonadal hormone concentrations, had girls self-report if they attained menarche, and had children self-stage their pubic hair (boys and girls) and breast (girls only) development according to images illustrating the different Tanner stages of development that were accompanied by the age-appropriate language we developed during pilot testing. We also assessed children's usage of electronic media, cigarettes and e-cigarettes. Finally, mothers reported the biological or non-biological father's education, weight and height. We also measured the intelligence quotient of 127 biological or non-biological fathers.

\section{FINDINGS TO DATE}

Baseline sociodemographic and perinatal characteristics of mother-child pairs who completed follow-up were similar to the original cohort (table 3 ). Children's mothers were predominately non-Hispanic white $(60.5 \%)$, collegeeducated $(48 \%)$, multiparous $(55.5 \%)$ and non-smokers during pregnancy $(84.0 \%)$.

To date, we have quantified concentrations of phenols, phthalate metabolites, metals, pesticides, PCBs, PBDEs, PFAS and tobacco smoke exposure biomarkers in maternal and child urine, blood or serum samples collected during pregnancy and through 8 years of age (table 4). Generally, environmental chemical biomarker concentrations in mothers during pregnancy and children at 8 years of age were similar to those of the US population at 
Table 3 Sociodemographic, perinatal and infant characteristics of HOME Study woman-child dyads eligible for follow-up $(n=441)$ and those who completed follow-up at 12 years of age $(n=256)^{\star}$

\begin{tabular}{lcc}
\hline Characteristic & $\begin{array}{l}\text { N (\%)/mean (SD) } \\
\text { at enrolment† }\end{array}$ & $\begin{array}{l}\mathbf{N}(\%) / \text { mean (SD) } \\
\text { at 12-year visit }\end{array}$ \\
\hline Maternal race & & \\
\hline $\begin{array}{l}\text { Non-Hispanic white } \\
\text { Non-Hispanic black }\end{array}$ & $130(53(69.4)$ & $88(34.4)$ \\
$\begin{array}{l}\text { American Indian, } \\
\text { Asian/Pacific/ }\end{array}$ & $27(6.1)$ & $13(5.1)$ \\
Hispanic & & \\
Missing & $31(7.0)$ & $0(0)$
\end{tabular}

Maternal age at delivery (years)

\begin{tabular}{|c|c|c|}
\hline $18-<25$ & $98(22.2)$ & $62(24.2)$ \\
\hline $25-<30$ & $122(27.7)$ & $72(28.1)$ \\
\hline $30-<35$ & $127(28.8)$ & $86(33.6)$ \\
\hline$\geq 35$ & $59(13.4)$ & $36(14.1)$ \\
\hline Missing & $35(7.9)$ & $0(0)$ \\
\hline \multicolumn{3}{|l|}{ Maternal education } \\
\hline Some high school & $40(9.1)$ & $21(8.2)$ \\
\hline High school or GED & $52(11.8)$ & $31(12.1)$ \\
\hline $\begin{array}{l}\text { Some college or } \\
\text { technical school }\end{array}$ & 104 (23.6) & $72(28.1)$ \\
\hline$\geq$ Bachelor's degree & $205(46.5)$ & $123(48.0)$ \\
\hline Missing & $40(9.1)$ & $9(3.5)$ \\
\hline \multicolumn{3}{|l|}{ Parity } \\
\hline Nulliparous & $171(38.8)$ & $103(40.2)$ \\
\hline Multiparous & $220(49.9)$ & $142(55.5)$ \\
\hline Missing & $50(11.3)$ & $11(4.3)$ \\
\hline \multicolumn{3}{|l|}{ Prenatal vitamin use } \\
\hline Never & 48 (10.9) & $28(10.9)$ \\
\hline Any & $344(78.0)$ & $212(82.8)$ \\
\hline Missing & $49(11.1)$ & $16(6.3)$ \\
\hline
\end{tabular}

Household income (US\$ per year)

$\begin{array}{lcc}<20000 & 86(19.5) & 58(22.7) \\ 20000 \text { to }<40000 & 75(17.0) & 45(17.6) \\ 40000 \text { to }<80000 & 128(29.0) & 77(30.1) \\ \geq 80000 & 104(23.6) & 64(25.0) \\ \text { Missing } & 48(10.9) & 12(4.7) \\ \text { Smoking during pregnancy† } & \\ \text { None } & 364(82.5) & 215(84.0) \\ \text { Any } & 64(14.5) & 34(13.3) \\ \text { Missing } & 13(2.9) & 7(2.7) \\ \text { Child sex } & & 143(55.9) \\ \text { Female } & 223(50.6) & 113(44.1) \\ \text { Male } & 183(41.5) & 0(0) \\ \text { Missing } & 35(7.9) & \end{array}$

Continued
Table 3 Continued

\begin{tabular}{lcc}
\hline Characteristic & $\begin{array}{l}\text { N (\%)/mean (SD) } \\
\text { at enrolment† }\end{array}$ & $\begin{array}{l}\mathbf{N}(\%) / \text { mean (SD) } \\
\text { at 12-year visit }\end{array}$ \\
\hline Infant birth weight (g) & $3329(643)$ & $3310(633)$ \\
$\begin{array}{l}\text { Gestational duration } \\
\text { (weeks) }\end{array}$ & $38.9(1.8)$ & $38.9(1.8)$ \\
\hline
\end{tabular}

*Among 441, some dropped out during pregnancy before administration of baseline questionnaire. Thus, baseline information was not available for some variables.

†Determined using serum cotinine concentrations at 16 or 26 weeks of gestation or at delivery. Women with a serum cotinine $\geq 3 \mathrm{ng} / \mathrm{mL}$ at any visit were classified as smokers. ${ }^{76}$ GED, General Educational Development; HOME, The Health Outcomes and Measures of the Environment.

the same time. ${ }^{6162}$ One notable exception is that serum perfluorooctanoate concentrations during pregnancy were higher in HOME Study women compared with pregnant women from the USA at the same time. ${ }^{14}$ We speculate that this might be due to ingestion of drinking water contaminated with perfluorooctanoate released by the DuPont Washington Works plant in Parkersburg, West Virginia. ${ }^{63}{ }^{64}$ We plan to measure concentrations of phenols, phthalate metabolites, organochlorine pesticides, PBDEs, PCBs and PFAS in urine or serum samples collected from children at 12 years of age.

At the most recent study visit, $91(82.1 \%)$ boys were Tanner stage 2 or greater for pubic hair development. Among girls, $136(97.1 \%)$ and $134(95.7 \%)$ were Tanner stage 2 or greater for breast and pubic hair development, respectively. In addition, $64(46.7 \%)$ girls achieved menarche at a median age of 11.8 years (range: 11.1-13.2) .

Average child anxiety and depression scores were typical for children of this age; $92(35.9 \%)$ and $27(10.5 \%)$ had scores indicative of potential anxiety and depressive disorders, respectively (table 5).

We observed the expected sexual dimorphism in lean/ adipose tissue mass that emerges during adolescence with girls having greater percent adipose tissue mass than boys. In addition, $25.4 \%$ of boys and $42.7 \%$ of girls were overweight or obese based on their body mass index z-score ${ }^{65}$ On average, glucose, insulin, triglyceride, lipoprotein and blood pressure values were typical for adolescents of this age. Ten percent to $33 \%$ of children had elevated glucose $(>100 \mathrm{mg} / \mathrm{dL})$, decreased high-density lipoprotein $(<40 \mathrm{mg} / \mathrm{dL})$ or borderline/high triglyceride concentrations $(>90 \mathrm{mg} / \mathrm{dL}){ }^{66}$

\section{ONGOING ACTIVITIES AND FUTURE PLANS}

Data collected from the recently completed phase of research at 12 years of age will allow examination of the relations between environmental chemical exposures and several adolescent health outcomes of high public health importance. Specifically, we received the United States 
Table 4 Description of environmental chemical biomarkers measured in HOME Study mothers during pregnancy and their children at 8 years of age (Cincinnati, Ohio; enrolled 2003-2006)

\begin{tabular}{|c|c|c|c|c|c|c|}
\hline \multirow[b]{2}{*}{ Chemical } & \multirow[b]{2}{*}{ Chemical class } & \multirow[b]{2}{*}{ Matrix } & \multicolumn{2}{|c|}{ Gestational (mother) } & \multicolumn{2}{|c|}{ Age 8 years (child) } \\
\hline & & & $\mathbf{N}$ & Median (25th, 75th) & $\mathbf{N}$ & Median (25th, 75th) \\
\hline Benzophenone-3 (ng/mL) & Phenols & Urine & 400 & $25(7.1,105)$ & 234 & $24(6.8,132)$ \\
\hline Triclosan (ng/mL) & Phenols & Urine & 400 & $16(6.4,49)$ & 234 & $12(3.8,35)$ \\
\hline Bisphenol A (ng/mL) & Phenols & Urine & 400 & $1.9(1.0,3.2)$ & 234 & $1.6(1,3.4)$ \\
\hline$\sum$ Paraben $(\mathrm{ng} / \mathrm{mL})^{*}$ & Phenols & Urine & 400 & $206(88,506)$ & NA & NA \\
\hline Mono-n-butyl phthalate (ng/mL) & Phthalates & Urine & 400 & $24(11,48)$ & 234 & $17(8.4,31)$ \\
\hline Monobenzyl phthalate $(\mathrm{ng} / \mathrm{mL})$ & Phthalates & Urine & 400 & $8.8(3.9,18)$ & 234 & $8.5(4.6,23)$ \\
\hline $\begin{array}{l}\text { Mono(3-carboxypropyl) phthalate } \\
\text { (ng/mL) }\end{array}$ & Phthalates & Urine & 400 & $2.3(1.1,3.8)$ & 234 & $4.1(2.3,7.9)$ \\
\hline Monoisobutyl phthalate (ng/L) & Phthalates & Urine & 400 & $4.7(2,9.1)$ & 234 & $11(5.6,20)$ \\
\hline Monoethyl phthalate $(\mathrm{ng} / \mathrm{mL})$ & Phthalates & Urine & 400 & $129(58,276)$ & 234 & $24(11,55)$ \\
\hline$\Sigma \mathrm{DEHP}(\mathrm{ng} / \mathrm{mL}) \dagger$ & Phthalates & Urine & 400 & $87(44,164)$ & 234 & $51(31,91)$ \\
\hline Arsenic (ng/mL) & Metals & Urine & 321 & $4.9(2.3,9.3)$ & NA & NA \\
\hline Mercury (ng/mL) & Metals & Blood & 388 & $0.6(0.4,1.0)$ & 203 & $0.2(0.2,0.4)$ \\
\hline Cadmium (ng/mL) & Metals & Urine & 321 & $0.1(0.07,0.2)$ & NA & NA \\
\hline Lead $(\mu \mathrm{g} / \mathrm{dL})$ & Metals & Blood & 400 & $0.7(0.5,0.8)$ & 203 & $0.7(0.5,1.0)$ \\
\hline$\sum \mathrm{DAP}(\mathrm{ng} / \mathrm{mL}) \ddagger$ & $\begin{array}{l}\text { Organophosphate } \\
\text { pesticides }\end{array}$ & Urine & 393 & $11(5.2,24)$ & NA & NA \\
\hline 3-Phenoxybenzoic acid (ng/mL) & Pyrethroid pesticides & Urine & 399 & $0.3(0.1,0.7)$ & NA & NA \\
\hline $\begin{array}{l}p, p^{\prime}-\text {-Dichlorodiphenyldichloroeth } \\
\text { ylene (ng/g lipid) }\end{array}$ & $\begin{array}{l}\text { Organochlorine } \\
\text { pesticides }\end{array}$ & Serum & 375 & $71(54,101)$ & 199 & $42(30,58)$ \\
\hline Hexachlorobenzene (ng/g lipid) & $\begin{array}{l}\text { Organochlorine } \\
\text { pesticides }\end{array}$ & Serum & 318 & $7.1(5.7,8.8)$ & 198 & $7.8(5.9,9)$ \\
\hline Oxychlordane (ng/g lipid) & $\begin{array}{l}\text { Organochlorine } \\
\text { pesticides }\end{array}$ & Serum & 310 & $5.1(3.6,7.2)$ & 174 & $2.8(2.3,5.4)$ \\
\hline trans-Nonachlor (ng/g lipid) & $\begin{array}{l}\text { Organochlorine } \\
\text { pesticides }\end{array}$ & Serum & 325 & $7.4(5.1,12)$ & 196 & $4.2(2.4,7.2)$ \\
\hline$\Sigma_{4}$ PCB (ng/g lipid)§ & $\begin{array}{l}\text { Polychlorinated } \\
\text { biphenyls }\end{array}$ & Serum & 363 & $30(21,43)$ & 198 & $12(7.3,22)$ \\
\hline $\begin{array}{l}\text { Polybrominated diphenyl } \\
\text { ether-47 (ng/g lipid) }\end{array}$ & $\begin{array}{l}\text { Polybrominated } \\
\text { diphenyl ethers }\end{array}$ & Serum & 375 & $19(11,35)$ & 199 & $19(10,39)$ \\
\hline $\begin{array}{l}\text { Perfluorohexane sulfonate (ng/ } \\
\mathrm{mL} \text { ) }\end{array}$ & $\begin{array}{l}\text { Perfluoroalkyl } \\
\text { substances }\end{array}$ & Serum & 370 & $1.5(0.9,2.3)$ & 200 & $1.3(0.9,2)$ \\
\hline Perfluorooctanoate (ng/mL) & $\begin{array}{l}\text { Perfluoroalkyl } \\
\text { substances }\end{array}$ & Serum & 370 & $5.4(3.6,7.6)$ & 200 & $2.4(1.7,3.1)$ \\
\hline $\begin{array}{l}\text { Perfluorooctane sulfonate (ng/ } \\
\mathrm{mL} \text { ) }\end{array}$ & $\begin{array}{l}\text { Perfluoroalkyl } \\
\text { substances }\end{array}$ & Serum & 370 & $13(9,18)$ & 200 & $3.6(2.7,4.9)$ \\
\hline Perfluorononanoate $(\mathrm{ng} / \mathrm{mL})$ & $\begin{array}{l}\text { Perfluoroalkyl } \\
\text { substances }\end{array}$ & Serum & 370 & $0.9(0.7,1.1)$ & 200 & $0.7(0.5,1)$ \\
\hline Cotinine $(\mathrm{ng} / \mathrm{mL})$ & $\begin{array}{l}\text { Tobacco smoke } \\
\text { exposure }\end{array}$ & Serum & 400 & $0.03(0.01,0.2)$ & NA & NA \\
\hline
\end{tabular}

* $\Sigma$ Paraben is the molar sum of methylparaben, propylparaben and butylparaben (expressed in $\mathrm{ng} / \mathrm{mL}$ of methylparaben concentrations). $\dagger \Sigma \mathrm{DEHP}$ (di-2-ethylhexyl phthalate) is the molar sum of its urinary metabolites MEHP, MEHHP, MEOHP and MECPP (expressed in ng/mL as MECPP concentration).

$\ddagger \Sigma D A P$ (dialkyl phosphate) is the molar sum of DEDTP, DEP, DETP, DMDTP, DMP and DMTP (expressed in ng/mL as DEDTP concentration). $\S \Sigma_{4}$ PCBs (polychlorinated biphenyls) is the sum of PCB 138/158, PCB 118, PCB 153 and PCB 180.

DEDTP, diethyldithiophosphate; DEP, diethylphosphate; DETP, diethylthiophosphate; DMDTP, dimethyldithiophosphate.; DMP, dimethylphosphate; DMTP, dimethylthiophosphate; HOME, The Health Outcomes and Measures of the Environment; MECPP, mono(2-ethyl5-carboxypentyl) phthalate; MEHHP, mono(2-ethyl-5-hydroxyhexyl) phthalate; MEHP, mono(2-ethylhexyl) phthalate; MEOHP, mono(2-ethyl-5oxohexyl) phthalate. 
Table 5 Descriptive statistics of internalising symptoms, body composition, and cardiometabolic risk factors among HOME Study children at the 12-year study visit: stratified by child sex (Cincinnati, Ohio, 2016-2018)

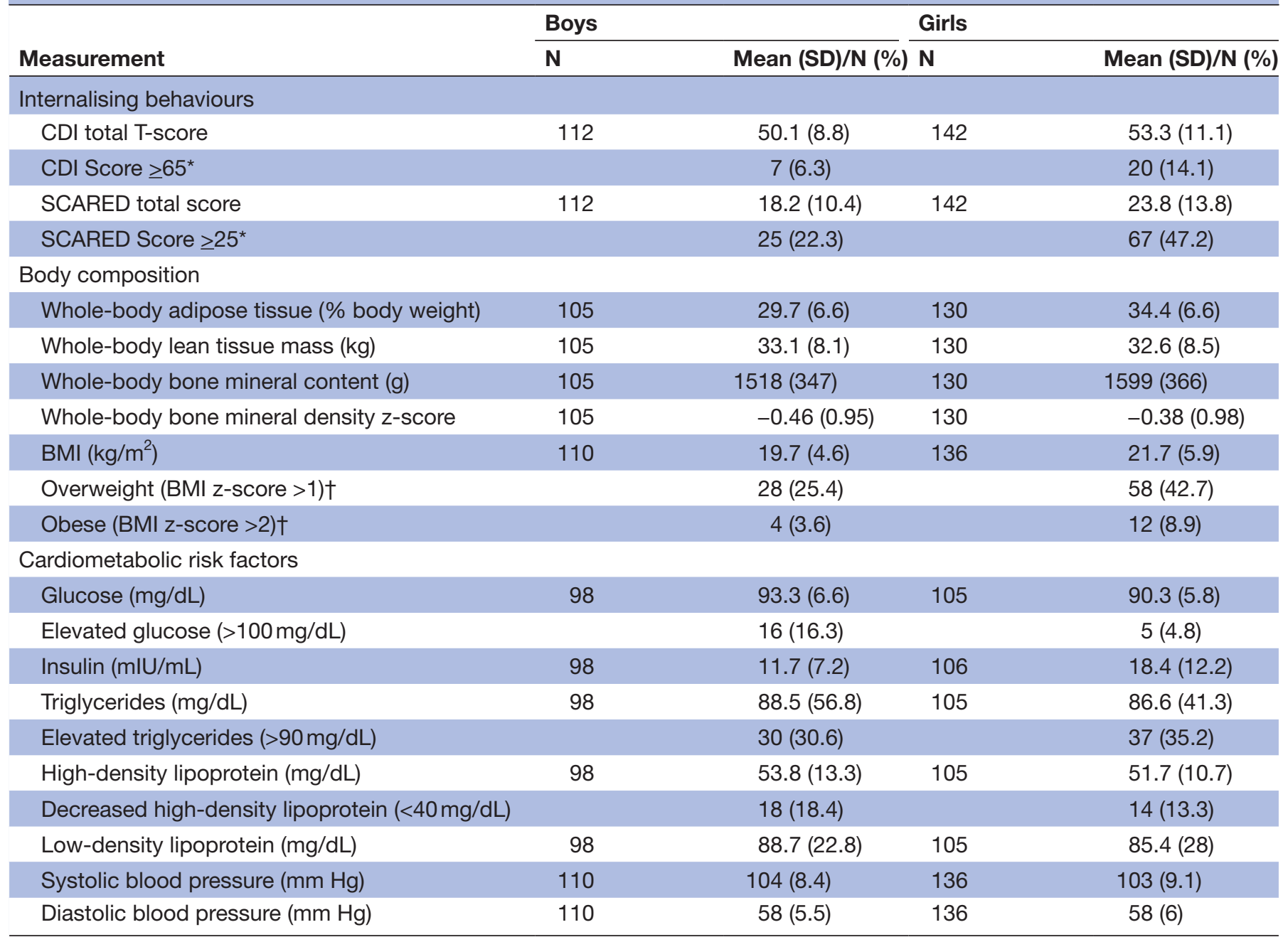

*Scores above these values are indicative of potentially clinically significant depression or anxiety disorders.

†Overweight and obesity are defined as having an age-specific and sex-specific BMI z-score $>1$ and $>2$ SD scores based on Centres for Disease Control and Prevention Growth Charts, respectively.

BMI, body mass index; CDI, Child Depression Inventory; HOME, The Health Outcomes and Measures of the Environment; SCARED, Screen for Child Anxiety Related Disorders.

National Institutes of Environmental Health Sciences (NIEHS) funding to assess the impact of:

- Early life PFAS exposures on early adolescent adiposity, cardiometabolic health and DNA methylation (R01 ES025214).

- Early life PFAS and PBDE exposures on adolescent internalising behaviours and neuroimaging outcomes (R01 ES027224).

- Early life organophosphate and novel brominated flame retardant exposures on neurodevelopment (R01 ES028277).

- Early life PFAS and phthalate exposures on bone health (R01 ES030078).

We are planning continued follow-up of HOME Study mothers and children and hope to invite them back for an in-person study visit when children are aged 16-18 and 17-21 years. During this visit, we will pilot new methods to remotely assess children's chemical exposures and health as they become adults. Our hope is to conduct follow-up on these children throughout adulthood.

\section{STRENGTHS AND LIMITATIONS}

One major strength of the HOME Study is the detailed phenotyping of several health outcomes that emerge in adolescence and are important determinants of health and well-being in early adulthood. ${ }^{67} 68$ Moreover, we have both maternal and child ratings of internalising symptoms and neurobehaviour, enhancing our ability to identify potential effects of chemical exposures on traits that might not be noticeable to parent-raters (eg, anxiety). A second strength is that we conducted state-ofthe-art measurement of many important determinants of adolescent health to control for confounding or identify potential mediators and modifiers. Finally, we conducted an extensive longitudinal assessment of exposure to $>100$ 
environmental chemicals or metals in gestation, infancy, childhood and adolescence.

One limitation of the HOME Study is the modest sample size, which reduces statistical power to estimate small effect sizes and limits the ability to examine clinical diagnoses. Second, and not unique to our study, is the loss to follow-up (58\% follow-up at the 12-year study visit). Reassuringly, our follow-up rates have increased in the latest three phases of study visits. In addition, sociodemographic factors did not substantially differ among participants who completed the 12-year study visit compared with the original cohort. Third, we collected limited information about fathers (or father figures), who play an influential role in adolescent health. Finally, our findings may not be generalisable to other populations as our eligibility criteria were not designed to ensure that our cohort was representative of births in the study region. However, most chemical biomarker concentrations among HOME Study participants are similar to pregnant women and children in the USA during the time of enrolment and follow-up. ${ }^{61} 69$

\section{COLLABORATION}

With funding from the NIEHS, we previously pooled data from the HOME Study with three other cohorts located in California and New York City. ${ }^{70-72}$ More recently, we jointly analysed or pooled data from the Maternal-Infant Research on Environmental Chemical (MIREC) Study, ${ }^{73}$ Early Autism Risk Longitudinal Investigation (EARLI) Study ${ }^{74}$ and Cincinnati Childhood Allergy and Air Pollution Study (CCAAPS). ${ }^{75}$ The goals of these collaborations have been to investigate how environmental chemicals, air pollution, nutritional factors and endogenous hormones influence childhood obesity and neurobehaviour. By pooling data or conducting joint analyses, we have attempted to replicate findings across cohorts to enhance causal inference and increase sample size to study chemical mixtures or uncommon phenotypes (eg, autism spectrum disorders).

The HOME Study Principal Investigators welcome new collaborations with other investigators and have actively engaged in collaborative data-sharing projects. Interested investigators should contact Drs Joseph M Braun (joseph_ braun_1@brown.edu) and Kimberly Yolton (kimberly. yolton@cchmc.org) to obtain additional information about the HOME Study, discuss collaborative opportunities and request a project proposal form. We are also designing a web portal that will allow exploration of study variables for the development of ancillary and secondary studies. The HOME Study Protocol Review Committee reviews proposed research projects to ensure that they do not overlap with extant projects and are an efficient use of scarce resources (eg, biospecimens).

\section{Author affiliations}

${ }^{1}$ Department of Epidemiology, Brown University, Providence, Rhode Island, USA
${ }^{2}$ Department of Environmental Health and Engineering, Johns Hopkins University Bloomberg School of Public Health, Baltimore, Maryland, USA

${ }^{3}$ Department of Radiology, Cincinnati Children's Hospital Medical Center, Cincinnati, Ohio, USA

${ }^{4}$ Department of Biostatistics, Epidemiology and Informatics, University of Pennsylvania, Philadelphia, Pennsylvania, USA

${ }^{5}$ Department of Pediatrics, Cincinnati Children's Hospital Medical Center, Cincinnati, Ohio, USA

${ }^{6}$ Faculty of Health Sciences, Simon Fraser University, Burnaby, British Columbia, Canada

Contributors JMB: drafted and edited the profile. JPB, KMC, AC, HJK, BPL, YX, $A W$ and $K Y$ : made substantive contributions and edits to the profile. $Y X$ : generated the sample sizes and preliminary findings. All authors substantially contributed to acquiring data from the most recent HOME Study visit described in this profile.

Funding The HOME Study was funded by National Institutes of Environmental Health Sciences grants R01 ES027224, R01 ES025214, R01 ES028277, R01 ES030078, R01 ES024381, R01 ES020349, P01 ES011261, R01 ES014575, and R01 ES015517.

Competing interests None declared.

Patient consent for publication Not required.

Ethics approval The institutional review boards of Cincinnati Children's Hospital Medical Center, the participating delivery hospitals and the CDC approved this study. During a face-to-face visit, research assistants explained study protocols to each prospective participant and completed a checklist to ensure women were fully informed about the trial. We obtained written consent for women and their children to participate in the trial. At the most recent visit, adolescents provided written informed assent after study protocols were explained and their questions answered.

Provenance and peer review Not commissioned; externally peer reviewed.

Data availability statement Data are available upon reasonable request. The HOME Study Principal Investigators welcome new collaborations with other investigators and have actively engaged in collaborative data sharing projects. Interested investigators should contact Drs Joseph M. Braun (joseph_braun_1@ brown.edu) and Kimberly Yolton (kimberly.yolton@cchmc.org) to obtain additional information about The HOME Study, discuss collaborative opportunities, and request a project proposal form. The HOME Study Protocol Review Committee reviews proposed research projects to ensure that they do not overlap with extant projects and are an efficient use of scarce resources (eg, biospecimens).

Open access This is an open access article distributed in accordance with the Creative Commons Attribution Non Commercial (CC BY-NC 4.0) license, which permits others to distribute, remix, adapt, build upon this work non-commercially, and license their derivative works on different terms, provided the original work is properly cited, appropriate credit is given, any changes made indicated, and the use is non-commercial. See: http://creativecommons.org/licenses/by-nc/4.0/.

\section{ORCID iD}

Joseph M Braun http://orcid.org/0000-0002-5239-3235

\section{REFERENCES}

1 Herbst AL, Ulfelder H, Poskanzer DC. Adenocarcinoma of the vagina. Association of maternal stilbestrol therapy with tumor appearance in young women. N Engl J Med 1971;284:878-81.

2 Hoover RN, Hyer M, Pfeiffer RM, et al. Adverse health outcomes in women exposed in utero to diethylstilbestrol. N Engl J Med 2011;365:1304-14.

3 Lanphear BP, Vorhees CV, Bellinger DC. Protecting children from environmental toxins. PLOS Med 2005;2:e61.

4 Axelrad DA, Bellinger DC, Ryan LM, et al. Dose-Response relationship of prenatal mercury exposure and IQ: an integrative analysis of epidemiologic data. Environ Health Perspect 2007;115:609-15.

5 Heindel JJ, Balbus J, Birnbaum L, et al. Developmental origins of health and disease: integrating environmental influences. Endocrinology 2015;156:3416-21.

6 Braun JM. Early-Life exposure to EDCs: role in childhood obesity and neurodevelopment. Nat Rev Endocrinol 2017;13:161-173.

7 Vrijheid M, Casas M, Gascon M, et al. Environmental pollutants and child health-A review of recent concerns. Int J Hyg Environ Health 2016;219:331-42. 
8 Etzel TM, Calafat AM, Ye X, et al. Urinary triclosan concentrations during pregnancy and birth outcomes. Environ Res 2017;156:505-11.

9 Kalloo G, Wellenius GA, McCandless L, et al. Exposures to chemical mixtures during pregnancy and neonatal outcomes: the home study. Environ Int 2020;134:105219.

10 Chen A, Yolton K, Rauch SA, et al. Prenatal polybrominated diphenyl ether exposures and neurodevelopment in U.S. children through 5 years of age: the home study. Environ Health Perspect 2014;122:856-62.

11 Stacy SL, Papandonatos GD, Calafat AM, et al. Early life bisphenol a exposure and neurobehavior at 8years of age: identifying windows of heightened vulnerability. Environ Int 2017;107:258-65.

12 Spanier AJ, Kahn RS, Kunselman AR, et al. Prenatal exposure to bisphenol A and child wheeze from birth to 3 years of age. Environ Health Perspect 2012;120:916-20.

13 Spanier AJ, Kahn RS, Kunselman AR, et al. Bisphenol a exposure and the development of wheeze and lung function in children through age 5 years. JAMA Pediatr 2014;168:1131-7.

14 Braun JM, Chen A, Romano ME, et al. Prenatal perfluoroalkyl substance exposure and child adiposity at 8 years of age: the home study. Obesity 2016;24:231-7.

15 Shoaff J, Papandonatos GD, Calafat AM, et al. Early-Life phthalate exposure and adiposity at 8 years of age. Environ Health Perspect 2017:125:097008.

16 Dorn LD, Hostinar CE, Susman EJ, et al. Conceptualizing puberty as a window of opportunity for impacting health and well-being across the life span. J Res Adolesc 2019;29:155-76.

17 Weaver CM, Gordon CM, Janz KF, et al. The National osteoporosis Foundation's position statement on peak bone mass development and lifestyle factors: a systematic review and implementation recommendations. Osteoporos Int 2016;27:1281-386.

18 Merikangas KR, He J-P, Burstein M, et al. Lifetime prevalence of mental disorders in U.S. adolescents: results from the National Comorbidity Survey Replication--Adolescent Supplement (NCS-A). J Am Acad Child Adolesc Psychiatry 2010;49:980-9.

19 Akresh R, Lucchetti L, Thirumurthy H. Wars and child health: evidence from the Eritrean-Ethiopian conflict. J Dev Econ 2012;99:330-40.

20 Holmqvist G, Pereira A. Famines and stunting: are adolescents the hardest hit? 2017. Available: https://blogs.unicef.org/evidence-foraction/famines-and-stunting-are-adolescents-the-hardest-hit/

21 Juraska JM, Sisk CL, DonCarlos LL. Sexual differentiation of the adolescent rodent brain: hormonal influences and developmental mechanisms. Horm Behav 2013;64:203-10.

22 Nations U. World population prospects: the 2017 revision, key findings and advance tables: United nations, 2017.

23 Sheehan P, Sweeny K, Rasmussen B, et al. Building the foundations for sustainable development: a case for global investment in the capabilities of adolescents. Lancet 2017;390:1792-806.

24 Braun JM, Kalloo G, Chen A, et al. Cohort profile: the health outcomes and measures of the environment (home) study. Int $J$ Epidemiol 2017;46:24.

25 Braun JM, Hornung R, Chen A, et al. Effect of residential LeadHazard interventions on childhood blood lead concentrations and neurobehavioral outcomes: a randomized clinical trial. JAMA Pediatr 2018;172:934.

26 Phelan KJ, Khoury J, Xu Y, et al. A randomized controlled trial of home injury hazard reduction: the home injury study. Arch Pediatr Adolesc Med 2011;165:339-45.

27 Birmaher B, Brent DA, Chiappetta L, et al. Psychometric properties of the screen for child anxiety related emotional disorders (scared): a replication study. J Am Acad Child Adolesc Psychiatry 1999;38:1230-6.

28 Spence SH. Structure of anxiety symptoms among children: a confirmatory factor-analytic study. J Abnorm Psychol 1997;106:280-97.

29 Kovacs M. The children's depression inventory. Eagan, MN: Pearson Assessments, 1992

30 Beck AT, Steer RA, Brown GK. Beck Depression Inventory - 2nd Edition (BDI-II. San Antonio: The Psychological Corporation, 1996.

31 Reynolds CK, Kamphaus RW. Behavior rating system for children. Third Edition. San Antonio, TX: Pearson, 2015.

32 Gioia GA, Isquith PK, Guy SC, et al. Brief rating inventory of executive function. Second Edition. Odessa, FL: Psychological Assessment Resources, Inc, 2015.

33 Constantino JN, Gruber CF. Social Responsiveness Scale-2.. In: Angeles L, ed. Ca: Western psychological services. 2nd Edition, 2012.

34 Gresham F, Elliott SN. Social skills improvement rating scales. SanAntonio, TX: Pearson Clinical Assessment, 2008.
35 Dahlberg LL, Toal SB, Swahn MH, et al. Measuing Violence-Related attitudes, Bhevaiors, and influences among Youths: a compendium of assessment tools. 2nd ed. Atlanta, GA: Division of Violence Prevention, National Center for Injury Prevention and Control, Centers for Disease Control and Prevention, 2005.

36 Instruments L. Grooved Pegboard. Lafayette, IN.

37 Sherman EMS, Brooks BL. Child and adolescent memory profile. Lutz, FL: Psychological Assessment Resources, Inc, 2015.

38 Wardle J, Guthrie CA, Sanderson S, et al. Development of the children's eating behaviour questionnaire. J Child Psychol Psychiatry 2001;42:963-70.

39 Carnell S, Wardle J. Measuring behavioural susceptibility to obesity: validation of the child eating behaviour questionnaire. Appetite 2007;48:104-13.

40 Sinha R, Chen J, Amir A, et al. Collecting fecal samples for microbiome analyses in epidemiology studies. Cancer Epidemiol Biomarkers Prev 2016;25:407-16.

41 Arora M, Austin C. Teeth as a biomarker of past chemical exposure. Curr Opin Pediatr 2013;25:261-7.

42 Berenson GS, Srinivasan SR, Bao W, et al. Association between multiple cardiovascular risk factors and atherosclerosis in children and young adults. The Bogalusa heart study. N Engl J Med 1998;338:1650-6.

43 McGill HC, McMahan CA, Gidding SS. Preventing heart disease in the 21st century: implications of the pathobiological determinants of atherosclerosis in youth (PDAY) study. Circulation 2008;117:1216-27.

44 Morrison JA, Friedman LA, Gray-McGuire C. Metabolic syndrome in childhood predicts adult cardiovascular disease 25 years later: the Princeton lipid research clinics follow-up study. Pediatrics 2007:120:340-5.

45 Jenny NS, Olson NC, Allison MA, et al. Biomarkers of key biological pathways in CVD. Glob Heart 2016;11:327-36.

46 Messiah SE, Arheart KL, Lipshultz SE, et al. Ethnic group differences in waist circumference percentiles among U.S. children and adolescents: estimates from the 1999-2008 National health and nutrition examination surveys. Metab Syndr Relat Disord 2011;9:297-303.

47 Ogden CL, Li Y, Freedman DS, et al. Smoothed percentage body fat Percentiles for U.S. children and adolescents, 1999-2004. Natl Health Stat Report 2011:43:1-7.

48 Perloff D, Grim C, Flack J, et al. Human blood pressure determination by sphygmomanometry. AHA Medical/Scientific statement. Circulation 1993;88:2460-70.

49 Gillman MW, Cook NR. Blood pressure measurement in childhood epidemiological studies. Circulation 1995;92:1049-57.

50 Vuong AM, Yolton K, Dietrich KN, et al. Exposure to polybrominated diphenyl ethers (PBDEs) and child behavior: current findings and future directions. Horm Behav 2018:101:94-104.

51 Kowalski KC, Crocker PR, Donen RM. The physical activity questionnaire for older children (PAQ-C) and adolescents (PAQ-A) manual. College of Kinesiology, University of Saskatchewan 2004;87.

52 Chandler JL, Brazendale K, Beets MW, et al. Classification of physical activity intensities using a wrist-worn accelerometer in 8-12-year-old children. Pediatr Obes 2016;11:120-7.

53 Crouter SE, Flynn JI, Bassett DR. Estimating physical activity in youth using a wrist accelerometer. Med Sci Sports Exerc 2015;47:944-51.

54 Institute NC. The healthy eating index - population ratio method 2017, 2017. Available: https://epi.grants.cancer.gov/hei/populationratio-method.html [Accessed 23 Aug 2019].

55 Matthews CE, Hagströmer M, Pober DM, et al. Best practices for using physical activity monitors in population-based research. Med Sci Sports Exerc 2012;44:S68-76.

56 Troiano RP, Berrigan D, Dodd KW, et al. Physical activity in the United States measured by accelerometer. Med Sci Sports Exerc 2008; $40: 181-8$

57 Kingsley SL, Kelsey KT, Butler R, et al. Maternal serum PFOA concentration and DNA methylation in cord blood: a pilot study. Environ Res 2017;158:174-8.

58 Kingsley SL, Walker DI, Calafat AM, et al. Metabolomics of childhood exposure to perfluoroalkyl substances: a cross-sectional study. Metabolomics 2019;15:95.

59 Derogatis L. Symptom Checklist - 90 - R. Minneapolis, MN: Pearson Assessments, 2004.

60 Kamphaus RW, Reynolds CK. Parenting relationship questionnaire. SanAntonio, TX: Pearson Clinical Assessment, 2008.

61 Woodruff TJ, Zota AR, Schwartz JM. Environmental chemicals in pregnant women in the United States: NHANES 2003-2004. Environ Health Perspect 2011;119:878-85. 
$62 \mathrm{CDC}$. Fourth national report on human exposure to environmental chemicals: centers for disease control. United States Department of Health and Human Services 2018.

63 Frisbee SJ, Brooks AP, Maher A, et al. The C8 health project: design, methods, and participants. Environ Health Perspect 2009;117:1873-82.

64 Emmett EA, Shofer FS, Zhang H, et al. Community exposure to perfluorooctanoate: relationships between serum concentrations and exposure sources. J Occup Environ Med 2006;48:759-70.

65 CDC. 2000 CDC growth charts: United States Hyattsville, MD, 2009 Available: http://www.cdc.gov/GrowthCharts/ [Accessed 1 Jul 2009].

66 Expert Panel on Integrated Guidelines for Cardiovascular Health and Risk Reduction in Children and Adolescents, National Heart, Lung, and Blood Institute. Expert panel on integrated guidelines for cardiovascular health and risk reduction in children and adolescents: summary report. Pediatrics 2011;128 Suppl 5:S213-56.

67 Paus T, Keshavan M, Giedd JN. Why do many psychiatric disorders emerge during adolescence? Nat Rev Neurosci 2008;9:947-57.

68 Singh AS, Mulder C, Twisk JWR, et al. Tracking of childhood overweight into adulthood: a systematic review of the literature. Obes Rev 2008:9:474-88.

69 CfDCaP CDC, Tables U. Fourth national report on human exposure to environmental chemicals. Updated Tables 2012 [updated 2012 http://www.cdc.gov/exposurereport/pdf/FourthReport UpdatedTables_Feb2012.pdf
70 Harley KG, Engel SM, Vedar MG, et al. Prenatal exposure to organophosphorous pesticides and fetal growth: pooled results from four longitudinal birth cohort studies. Environ Health Perspect 2016;124:1084-92.

71 Engel SM, Bradman A, Wolff MS, et al. Prenatal organophosphorus pesticide exposure and child neurodevelopment at 24 months: an analysis of four birth cohorts. Environ Health Perspect 2016;124:822-30.

72 Buckley JP, Engel SM, Braun JM, et al. Prenatal phthalate exposures and body mass index among 4- to 7-year-old children: a pooled analysis. Epidemiology 2016;27:449-58.

73 Li N, Arbuckle TE, Muckle G, et al. Associations of cord blood leptin and adiponectin with children's cognitive abilities. Psychoneuroendocrinology 2019;99:257-64.

74 Newschaffer CJ, Croen LA, Fallin MD, et al. Infant siblings and the investigation of autism risk factors. J Neurodev Disord 2012;4:7.

75 Sears CG, Mueller-Leonhard C, Wellenius GA, et al. Early-Life exposure to traffic-related air pollution and child anthropometry. Environmental Epidemiology 2019;3:e061.

76 Benowitz NL, Bernert JT, Caraballo RS, et al. Optimal serum cotinine levels for distinguishing cigarette smokers and nonsmokers within different racial/ethnic groups in the United States between 1999 and 2004. Am J Epidemiol 2009;169:236-48. 